\title{
MONITORING AND PREDICTING SLOPE INSTABILITY: A REVIEW OF CURRENT PRACTICES FROM A MINING PERSPECTIVE
}

\author{
Upasna P. Chandarana ${ }^{1}$, Moe Momayez ${ }^{2}$, Keith W. Taylor ${ }^{3}$ \\ ${ }^{1}$ Ph.D. Candidate, Mining \& Geological Engineering, University of Arizona, Arizona, USA \\ ${ }^{2}$ Associate Professor, Mining \& Geological Engineering, University of Arizona, Arizona, USA \\ ${ }^{3}$ M.S. Candidate, Mining \& Geological Engineering, University of Arizona, Arizona, USA
}

\begin{abstract}
Mines have an inherent risk of geotechnical failure in both rock excavations and tailings storage facilities. Geotechnical failure occurs when there is a combination of exceptionally large forces acting on a structure and/or low material strength resulting in the structure not withstanding a designed service load. The excavation of rocks can initiate rock mass movements. If the movement is monitored promptly, accidents, loss of ore reserves and equipment, loss of lives, and closure of the mine can be prevented. Mining companies routinely use deformation monitoring to manage the geotechnical risk associated with the mining process. The aim of this paper is to review the geotechnical risk management process. In order to perform a proper analysis of slope instability, understanding the importance as well as the limitations of any monitoring system is crucial. The geotechnical instability analysis starts with the core understanding of the types of failure, including plane failure, wedge failure, toppling failure, and rotational failure. Potential hazards can be identified by visually inspecting active areas as required, using simple measurement devices installed throughout the mine, and/or remotely by scanning excavations with state-of-the-art instrumentation. Monitoring systems such as the survey network, tension crack mapping and wireline extensometers have been used extensively, however, in recent years, technologies like ground-based real aperture radar, synthetic aperture radar, and satellite-based synthetic aperture radar are becoming commonplace. All these monitoring systems provide a measurable output ready for advanced data analysis. Different methods of analysis reviewed in this paper include inverse velocity method and fuzzy neural network.
\end{abstract}

Keywords: Geomechanics, Slope Instability, Monitoring, Radars, Slope Failure $* * *$

\section{INTRODUCTION}

The earth surface is a complex and dynamic system subject to hazards resulting from naturally occurring or man-made events. In our daily lives we encounter slopes created by geological and/or geomorphological processes. Roads running through mountains, mine pit walls, and other slopes cutting into rocks are examples of man-made slopes. Along with gravity, the strength of the rock including intact and fracture strength, orientation, spacing and length of discontinuities in the rock, pore pressure, geology, hydrology, surface conditions and ground behavior play a significant role in natural or engineered slope failures. A slope failure occurs when rock and/or soil collapses abruptly due to weakened self-retain ability of the earth. The constant gravitational force acting on materials resting on inclined surfaces is the primary factor for triggering events such as landslides, rockslides, and avalanches. Any slope failure such as rockslides and landslides can prove hazardous to people living in the area affected by the instability. It is vital to monitor these slopes and when possible, issue forewarnings of impending failure.

A career in the mining industry exposes employees to risks daily. One significant consequence of risk exposure at a mine site is fatalities. Safety and risk assessment are high priorities of the mining industry. Several types of risks are involved in any mining operation, but in recent years geotechnical risks have been highly researched, and its unpredictability has made it a crucial topic. The research mainly focuses on mitigating risks by precisely predicting geotechnical hazards. Geotechnical risks, also known as slope instabilities, can cause significant injury to employees, harm to the environment, loss of production, and deterioration of a company's reputation.

Surface mining operations are immensely affected by the steep design of engineered pit slopes. Large-scale failures resulting from unstable pit slopes can be hazardous or in the worst case cause loss of lives of miners who work directly below unstable areas. Unstable areas are found at any mining operation, but sudden ground movement can destroy property and threaten safety [1]. In an environment with unstable ground, small rock fall can also cause fatal injuries to employees working without any cover; bigger landslides could cause injuries to workers enclosed in larger mining equipment if proper precaution is not taken.

Most rock failures show an accelerating velocity trend to indicate ground movement. If observed, these accelerating trends have similar mathematical patterns, but the factors affecting movement are different. Combining known properties of a new site with historical data of previous failures can increase the predictability of a failure. A higher failure predictability increases the safety at the mine site, improves production rates and helps save time and precious resources. 


\section{FAILURE MODES AND MECHANISMS}

Slope failures are significant natural hazards that occur due to forces like gravity, groundwater, weather conditions, geology, surface conditions and many more. Commonly seen slope failure types include plane, wedge, toppling, and rotational failures. Most failures are controlled by the orientation and spacing of discontinuities in the rock mass in relation to the slope face. There could be a single or multiple discontinuities intersecting in the rock mass forming a failure mode [2].

\subsection{Plane Failure}

A plane failure occurs when a discontinuity in the rock mass strikes nearly parallel or parallel to the slope face at an angle steeper than the internal friction angle. Discontinuities like bedding planes, faults, joints and the interface between different rock types usually from a failure surface. When the angle of the discontinuity is steeper than the friction angle, the loose or weak material above the joint sets slides along the discontinuity under stress conditions and the intense gravitational force. If the dip direction of a planar discontinuity is within $+/-20^{\circ}$ of the dip direction of the slope face, it will serve as a favorable plane failure condition.If the dip direction of the discontinuity is lower than that of the slope face, and the dip direction of the discontinuity is greater than that of the friction angle, it can effortlessly induce a plane failure [2].

\subsection{Wedge Failure}

Wedge failure is similar to a plane failure and occurs when the rock mass slides along one or more discontinuities. Usually, wedge failure includes two intersecting faults or joints, both of which dip out of the slope face at an oblique angle, forming a wedge-shaped block. Most often, for a wedge failure to occur the rock mass must consist of two or more discontinuities whose lines of intersection are almost perpendicular to the strike of the slope and dip towards the slope of the face. In this failure mode, it is required to have at least one discontinuity with a dip angle greater than the internal friction angle for the material to slide down the discontinuity.

\subsection{Toppling Failure}

Columns of rocks are formed by steeply dipping discontinuities in the rock mass. A rotation ofthese columns about a mostly fixed point near the base of the slope, followed by slippage between layers, causes a toppling failure. Toppling occurs when the center of gravity of these structures exceed the dimensions of their base. A necessary precursor of the toppling failure is to have the jointed rock masses closely spaced and steeply dipping, with discontinuities dipping away from the slope face. In an active mining operation, a toppling failure might occur when the overburden confined rock is removed by excavation, causing partial relief of the constraining stresses.

\subsection{Rotational Failure}

Rotational failure, sometimes termed circular failure [3], indicates that the failure takes place along a circular arc. This failure typically occurs in weak rock or soil like material. As pointed out by Hoek \& Bray[3], and Hoek [4], rotational failure could also occur in rock slopes with no substantial structural patterns in the slope such as a highly fractured rock mass with no predominate orientations of discontinuities. The movement of material along a curved surface is known as a rotational slide. In a rotational slip, the shape of the failure surface may be a circular arc or a noncircular curve. The condition for a rotational failure is that the individual particle in soil or rock mass should be subtle compared to the size of the slope and these particles are not interlocked because of their shape [3]. Rotational failure is a very plausible failure mode for large-scale slopes, such as those found in open pit mining. Rotational failure in a largescale slope would probably involve failure along preexisting discontinuities with some portions of the failure surface passing through intact rock.

The mechanism of plane failure is relatively simple to understand. Failure occurs when the supporting rock mass, below or around any discontinuity daylighting into the pit, moves. The location and orientation of the discontinuity are the primary governing factor for the shape and size of the failure. The strength and stress conditions of the intact rock, as well as the groundwater conditions around it, govern the possibility of a failure [5]. The same mechanism applies to a wedge failure, the significant difference between a plane and wedge failure being two or more intersecting discontinuities are present in a wedge failure. Sjoberg [5] also states that the driving forces behind more complex failure modes such as step path and rotational failure in principal are the same, but the actual mechanism of failure is harder to quantify.

\section{AIM OF SLOPE STABILITY ANALYSIS}

Geomechanics and slope stability are significant factors in the mining industry in light of current pit slope angles and the future possibility of steepening these angles. The main aims of slope stability analysis include but are not limited to:

- Understanding the development of natural and manmade slopes over the life of the mine. A geomechanical engineer must know how natural slopes may affect engineered pit slopes day-to-day and over the life of the mine. The designed slopes must be stable while mining the current phase and remain stable through the last mining phase of any area in a pit.

- Understanding the influence of environmental factors like wind, rainfall, the strength of the rock, vegetation, etc. on the failure mechanisms that might be affected by these factors.

- Enabling the redesign of failed slopes. Regardless of all implemented precautions, risks are involved in slope design and failures might occur. After a failure an understanding of slope stability helps in the redesign of failed slopes. 
- Allowing for the steepest possible engineered slopes while providing the safest work environment. Challenges faced when steepening slopes include slope failure, loss of production, and extra mining costs for failed material and remediation projects.

\section{IMPORTANCE OF MONITORING}

The excavation of rocks can initiate rock mass movements which must be carefully monitored to prevent accidents, loss of ore reserves and equipment, closure of the mine and sometimes loss of lives [6]. Rock mass properties, geological structures, and hydrologic conditions are important considerations while designing a safe and efficient mining operation [1]. An engineered factor of safety is used to control damage to equipment and risk of injury from rock all and slope failure. When considering the factor of safety, there is a need to control costs. Steepened pit walls can minimize and control operational costs by reducing waste removal. However, steeper walls create a greater potential for slope stability problems. Mines utilize benches and berms to catch falling material, control blasting practices to minimize unnecessary fracturing, and manage groundwater to help stabilize the slopes. However, unidentified geological structures, unexpected weather conditions, or seismic activities can cause well-designed slopes to fail. Due to this uncertainty regular visual inspections and systematic monitoring should be applied to provide early warning signs of failures [1].

Girrard [7] states, despite all these risks associated with high walls and slope failures, there are several ways to reduce these hazards:

1. Safe geotechnical designs

2. Adequate bench design

3. Monitoring devices with the ability to provide warning of approaching failures

4. Satisfactory scaling of loose material from high walls.

Geologic uncertainty necessitates precautionary measures to reduce the hazards associated with slope failure. Thorough monitoring of slopes and high walls for early warning signs of failure or rapid displacement is crucial for protecting workers and equipment [7]. Although geotechnical considerations are made with a higher factor of safety to make working environment safer, there canal ways be unexpected and/or unknown geologic structures, abnormal weather patterns, or seismic shock causing a sudden failure. Proper use of monitoring systems can reduce uncertainty and help in the development of appropriate action plans.

Using monitoring systems for risk assessment analysishas various advantages. Monitoring can help validate the overall mine plan and design. Measurements acquired from slope monitoring equipment aids in the decision to maintain, steepen or reduce slope angles while keeping safety and financial benefits intact [8]. Thus, the results of slope angle analysis can impact the future mine plan and design. Monitoring provides visual proof to management of slope stability and safety, ensuring the wellbeing of mining equipment, production and above all mine personnel. Most monitoring systems also have the ability to set off a warning alarms indicating unstable areas: this ensures that precautionary measures are promptly considered. Additionally, rates of movement of the unstable zones are easily acquired from the monitoring system, providing the approximate time required to clear the area in case of a big failure. Given adequate warning time in advance of a failure, mines can save a multitude of resources.

Girrard [7] states, some of the more common warning signs of slope instability include:

- Tension Cracks: the emergence of cracks at the top of a bench or highwall is a sign of weakness. These cracks form where material from the slope has moved into the pit. It is crucial to regularly check the crests of the high walls around the working areas as these cracks might be invisible on the pit floor. It is beneficial to install prisms on benches while the benches are excavated to enable proper monitoring in the future.

- Scarps: usually formed or found in areas where the material has moved down in a vertical or nearly vertical trend. The vertically movingmaterial and the face of the scarp maybe very unstable and should be monitored accordingly.

- Abnormal water flows: sudden changes in the precipitation levels or water flows may easily aggravate slope movement. Spring run-off from snow and rainfall are commonly cause adverse effects on slopes. However, changes in constant flow rate of dewatering wells or unidentified changes in the piezometer measurements might indicate a subsurface movement that cut through a perched water table. Water can also penetrate fractures and accelerate the weathering process. Freeze-thaw cycles may loosen the high wall material by expanding the water filled in joints.

- Bulges or creep: protruding material appearing on a slope indicates creep or slow subsurface movement. Changes in the vegetation of the area may suggest creep as well.

- Rubble at the toe: is an indicator of recent movement. Effort is required to determine which portion of the slope moved and whether more material may collapse.

It is important to note that every mine is unique and monitoring techniques should be chosen to fit the specific needs of each mine. Sometimes it is necessary to choose several monitoring techniques for a single mine based on varying rock types and additional mine-specific criteria.

\section{TYPES OF MONITORING}

Mining companies routinely use deformation monitoring to manage geotechnical risks. Deformation monitoring enables the identification of the distinctive accelerating trend of a progressive failure and provides time to make a plan. Early identification of geotechnical hazards ensures sufficient time is available to remove people and equipment from the area exposed to the risk. Additionally, deformation monitoring enables engineers to confirm that geotechnical structures perform as designed by ensuring deformations occur at a steady rate. If the observed deformation is comparable to 
design assumptions, deformation may not be accelerating to a progressive failure. Additional investigation and analysis allow engineers to determine if any mitigation is needed to achieve the mine design, or deformation is manageable without additional mitigation.

In recent years ground-based radar interferometry has become a popular technology for monitoring displacement of landslides and slopes in open pit mines [9]. Pit slopes are remotely observed with a ground-based interferometric radar, installed in a location witha direct or suitable view of the area of interest. The ground-based interferometric radars can be categorized into two types: real aperture radar and synthetic aperture radar.

Radars can detect the distance and the direction of a target by transmitting and receiving electromagnetic waves. The distance is calculated by evaluating the time of flight of a returning electromagnetic pulse [9]. This mechanism can be used for solid surfaces only. For bodies of water the radar signal is absorbed and will not reflect back.

Commonly used monitoring systems are broken down into categories based on the types of measurement they provide.

\subsection{Visual Measurements}

Visual observations are among the best resources any monitoring program can possess. At a mine site, a sharp eye to new changes in slopes or high walls is very beneficial. A geotechnical engineer can perform a visual inspection with a routine walk or drive around the pit, access ways, high walls, and crests close to potentially dangerous working areas [6]. The engineer should be able to compare the previous visit observations with the latest visual inspection and make sure that no visible differences of movements are missed.

\subsection{Surface Measurements}

\subsubsection{Survey Network}

The use of total stations is the most common and least expensive method to monitor slopes in an open pit mine. Three major requirements allow this technique to identify steady versus unsteady areas of an active open pit. 1) A set of reference areas or controlled points with known $\mathrm{X}, \mathrm{Y}$ and $\mathrm{Z}$ coordinates are required. Thesepoints should be identifiable as steady points or areas with minimal to zero movement. Reference points should be visible from the transfer or survey station. 2) Survey stations are setup or built in a place with direct line-of-sight to the reference points and area of interest. 3) Prisms must be installed within line-of-sight to the survey station. Prisms are usually fitted on top of a rod and pointed towards the survey station. If the prisms are not pointed towards the survey station or are not in direct line-of-sight, the survey station cannot pick up any movements of the prism. It is desirable that the measurement direction is towards the total station so the distance readings approximate the actual slope change [10].
It is ideal to place prisms in every possible location of interest, but if few prisms areavailable, they should be placed in the unstable areas of the pit slope with one or more control points [7]. These prisms are placed so they can be targeted by a total station. Total stations measure the angles and distances from the survey station to the prisms at a set time to establish a history of movement on the slope. A total station collects the data promptly and the data is transmitted from the pit to the computer fitted with analysis software. The data can also be collected manually from the total stations if needed. The data from the prisms comes in the form of XYZ coordinates to show movement and its direction, giving the user a 3-D movement and not just the line of sight movement. This monitoring system is subdivided into three parts: data collection, data transmission, and data analysis[8]. This system is relatively inexpensive compared to some of the other monitoring systems, but the biggest sources of error are caused by atmospheric factors such as dust and haze, human error, and damage to prisms. Manufacturers publish the accuracy and error limits of their equipment, to reduce error, surveying instruments need careful adjustment and correct calibration according to the manufacturer's instructions to ensure equipment accuracy and reliability [7]. Displacement of the survey station can also affect measurement accuracy [6]. It is imperative that total stations are set where the ground is steady or measurements will be inaccurate. If the total station is moving it will project a large area is moving on a slope even if the area is stable. All prisms monitored by the total station in an unstable area will appear to move.

Each mine can use the rock type present as its unique identifier. The rock type present at a mine defines the monitoring frequency required and the primary objective of the monitoring program. If the rock type allows slow movement, the monitoring frequency could be as low as once a month; if the rock is highly fractured it might require a monitoring frequency of $3-4$ times per day.

\subsubsection{Tension Crack Mapping}

Tension cracks may be easily visible in areas of concern. Measuring and monitoring the changes in width and direction of crack propagation is required to establish the bounds of the unstable area [7]. The easiest way to observe tension cracks is to first flag the area containing the tension cracks, surround the cracks with cones, and paint the cracks with spray paint to make them obvious. New crack formations are easier to identify iftension cracks are flagged as they form.Wooden stakes should be placed oneither side of the cracks as they form to measure width. As time progresses the measurement between the wooden stakes will identify if the width of the crack is growing or remains steady.

\subsubsection{Wireline Extensometer}

Wireline extensometers are useful in monitoring tension cracks. Typical setup of an extensometer includes a wire anchored to the unstable area and attached to the monitor and pulley station on the stable section of ground. The 
anchor is connected to the side of the tension crack with an open or free face that can move whereas the pulley system is on the stable side of the tension crack. The wire runs over the pulley and the tension created by the suspended weight of the unstable ground pulls the cable. Movement generatedis recorded electronically or manually. The extensometer wire length should be limited to approximately $60 \mathrm{~m}(197 \mathrm{ft})$ to keep errors due to sag at a minimum [11].

Most of the extensometers have a digital readout system that records movement and transmits data to monitoring computers. A small solar panel system can easily power an extensometer. Readings can be taken manually by site personnel or in an electronic data logger. Additionally, the electronic extensometers can be linked to an alarm system to warn if there is significant movement. Alarms require a minimum threshold and once that threshold is breached will sound automatically to warn of potential slope instabilities. Under normal conditions, this works well, but the alarms can be accidentally triggered by falling rocks, birds or animals [6]. Also, further cracking might weaken the entire area making the recordings of the movement inaccurate. However, extensometers are economical to use and very useful in defining the relative changes between points either on the surface or in a pit [12].

\subsection{Remote Monitoring Technologies}

\subsubsection{Ground-Based Real Aperture Radar}

Ground-based radar is monitoring technology used as a geotechnical risk management tool. The monitoring systems described above are used as risk management tools in geomechanical analysis, but this point-to-point data cannot give the essential overall coverage that ground-based radar provides. These monitoring systems are very useful, but the spacing of the systems might not provide the required data for slope movement analysis. McHugh [1] says, point-bypoint monitoring of each potential failure block on a large mine slope is impractical, but a new generation of scanning laser range finders would address the problem of undersampling in detecting movement over a larger area.

Displacement measurements can track mass movements of failing slopes and help mitigate the risks being caused by them. The ground-based approach has the distinct advantage of high resolution derived from a smaller radar footprint and a high sampling rate to provide real-time displacement detection.

Real aperture radar consists of a satellite dish that moves both horizontally and vertically to scan high walls and other areas of interest. The radar dish uses a single twodimensional (2D) scanning antenna. The single pencil beam antenna scans in two dimensions over the high wall. The antenna scans the high wall in small areas; each area is known as a pixel. Each pixel is a different size due to the difference in distance from the wall to the radar at each point. The different size of the pixel enables us to see it uniformly when looking at the results of a three-dimensional (3D) space in $2 \mathrm{D}$. At each pixel location a radar signal is transmitted then the radar echo is received and processed.
The radar signal phase from each transmitted signal is recorded. Each pixel is continuously scanned. Depending on the size of the high wall it can take anywhere from 2 to 20 minutes to scan the whole area. When the radar scans a wall it starts left to right and bottom to top, creating a single line path. Each scan is compared to the previous scan; the difference in the phase between scans is related to face movement with an estimated correction based on weather conditions. This approach requires a high-precision 2D scanning system and an exceptionally phase-stable radar, both of which add to the expense of the system [1].

The major downside of using this monitoring system is phase ambiguity. Phase ambiguity occurs when the high wall moves faster than the time between scans. Specifically, the system scans a region of the wall and compares the phase of the return signal at each footprint (pixel) with the previous scan to determine the stability of the slope and the nature of the movement. If the displacement in the slope face at a given pixel between two scans is greater than half the wavelength of the radar, a unique solution cannot be determined. As an example, for a10 $\mathrm{GHz}$ radar that scans $180 \mathrm{~mm} / \mathrm{hr}$ at 10 minutes per scan, one half of the radar wavelength is approximately $15 \mathrm{~mm}$. Now, if the wall moves faster than $15 \mathrm{~mm}$ between scans there is the possibility of phase ambiguity. The system software solves the problem by predicting the velocity of each region on the slope face for the next scan using curve fitting techniques and a history of previous velocities. The measured phase is then compared to the predicted value and the actual velocity is determined in real-time. Despite this downside, real aperture radars provide full coverage without the need to install reflectors or additional instruments on the slope face while operating reliably in the presence of atmospheric disturbances such as rain, dust, and smoke.

\subsubsection{Synthetic Aperture Radar}

By simulating a much larger antenna than could be physically manufactured, Synthetic Aperture Radar (SAR) imaging can achieve higher spatial density over large areas in any light condition and almost all weather conditions. In recent years, SAR imaging is used in satellites and aircraft to overcome the antenna size limitations of real aperture radar. The data collected from SAR imaging is recorded in the form of amplitude and phase value of the return signal. The amplitude can be used to create pseudo-optical images or to analyze reflectivity of the surface. Phase value is significant when monitoring large areas. The phase value from a single SAR image does not give enough information to detect any movement but when two or more images are compared the differences in phase values show the total amount of movement that has taken place during the allotted time. If looking at deformation over an extended period, all consecutive measurements of the phase difference must be added for an accurate estimate of the total deformation. All SAR equipment use similar background technology to display movement of any area being monitored. Currently, there are two types of SAR utilized in the mining industry: ground-based SAR and satellite based SAR. The mechanisms of the ground based synthetic aperture and satellite based synthetic aperture are described below. 


\subsubsection{Ground Based Synthetic Aperture Radar}

SAR is a ground-mapping radar originally designed for aircraft and satellite use. Since the 1970's, exploration geologists have benefited from SAR imagery. SAR can generate terrain maps to produce high-quality digital elevation models and to detect surface disturbances or changes[6]. This type of monitoring uses a dual receiver antenna and one-dimensional (1D) scanning. A fan-beam is transmitted from the antenna to illuminate a vertical face over a small horizontal distance. Unlike real aperture radar, ground-based SAR only moves in one direction to collect all the readings: it covers a small horizontal distance while moving from left to right for each scan and then starts again from its original position. Similar to the ground based real aperture radar, SAR repeatedly scans over time but just in a horizontal sweep manner, a short baseline distance separates the two receiver antennas. The radar's range resolution enables vertical resolution of the face [1]. The interferometric phase difference between the receiver antennas is recorded between each scan position. Since the radar is stationary, the differential phase between scans can be easily calculated to show deformation on the high wall. This approach does not have the stringent long-term phase stability requirements of the pencil-beam, and since it scans in a single dimension, the scanning system is less expensive than a real aperture radar [1].

\subsubsection{Satellite Based Synthetic Aperture Radar}

Satellite-based InSAR (Interferometric Synthetic Aperture Radar) is a monitoring technology that can be a geotechnical risk management tool just like a ground based real aperture radar. It compliments existing monitoring technology by providing broad coverage, high spatial density, and high precision at a relatively low cost. While satellite-based InSAR does not monitor in real time, the technology has progressed to where measurements can be consistently taken every five to ten days. This frequency allows the monitoring data to be used proactively to make decisions regarding hazard identification, ground-based monitoring placement, and design performance.

In a single SAR image, the phase value is of little value. However, when compared to a subsequent image the phase difference from one image to the next can be interpreted as a displacement value, towards the satellite, for each pixel. This process of interferometry is the same as that used by ground-based radars to measure deformation.

The phase value of the return signal, measured from 0 to $2 \pi$, is compared to the previous phase value by subtraction. The phase difference between two images can be related to deformation by the wavelength of the signal. The resulting phase difference image is called an interferogram. In areas of deformation, the phase value of adjacent pixels will differ by the corresponding relative difference in displacement in the direction of the radar position. When the pixels are colored according to the phase value, movement typically results in a repeating pattern of concentric rings (Fig-1).
Each consecutive ring of value $2 \pi$ corresponds to deformation equal to one-half the value of the wavelength. Any deformation is measured twice: as the signal approaches the ground, and again as the signal reflects from the ground back to the radar. Concentric rings of value $2 \pi$ can be counted and added together to measure deformation greater than the wavelength, to the extent that the rings can be resolved in the interferogram. This process is called phase unwrapping [13].
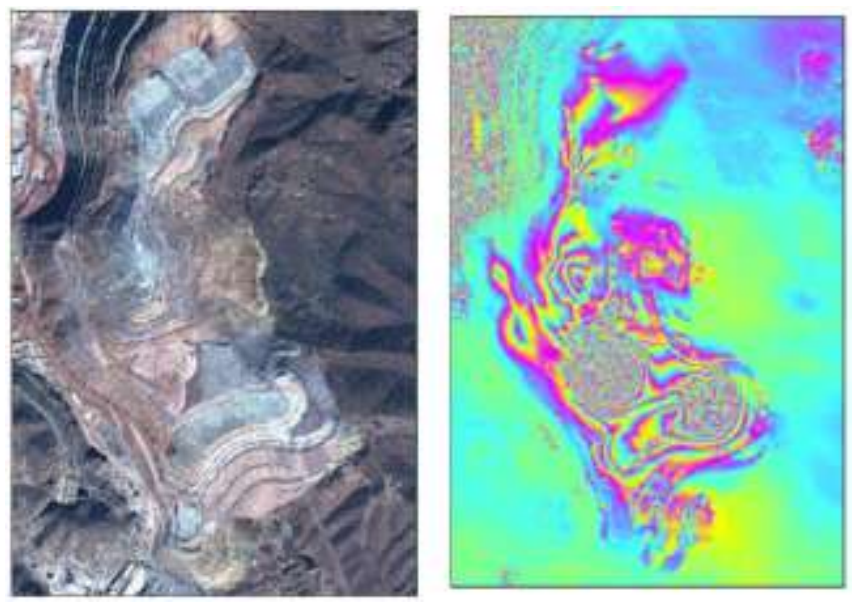

Fig-1: Aerial photography of mine area and associated 11day interferogram

In mining applications, satellite based InSAR can monitor deformation in the major geotechnical structures that are difficult to monitor with ground-based equipment. It is important to track the stability of large tailings impoundments, stockpiles, and the perimeter of open pits because these locations contain or are built near processing facilities or other mine infrastructure, access roads, and public facilities or residential areas that may be near the property boundaries. Instabilities in these structures need not be enormous to have a large impact. These geotechnical structures can be kilometers long so there is a large area to cover. The soil-like nature of stockpiles and tailings impoundments means that point-based monitoring like prisms or GPS stations would be effective at measuring deformation because they can measure in the direction of the movement independently of the source of measurement. But point-based monitoring is impractical for large areas where movements of small areas need to be detected. The broad coverage provided by ground-based radar systems is suitable for detecting small movement areas. However, the line of sight geometry is not ideal because the majority of the surface to be monitored is flat, and close to parallel to the look direction of the ground-based radars. Additionally, the large size of some geotechnical structures combined with the relatively high capital and operating cost of ground based radar make them cost prohibitive.

Satellite-based InSAR addresses all the monitoring issues presented by ground-based monitoring. The spatial resolution is between $3 \mathrm{~m}$ to $10 \mathrm{~m}$ between measurement points, depending on the satellite used for imaging. The minimum detectable area is then on the order of $10 \mathrm{~m} \times 10 \mathrm{~m}$. The image size is on the order of $15 \mathrm{~km} \times 30 \mathrm{~km}$, depending 
on the satellite used. The image size is broad enough to cover even large mine properties. The steep satellite look geometry is ideal for measuring deformation on large flat areas. Finally, the annual expense of acquiring and processing the images is similar to the annual maintenance cost for one ground-based radar. This issignificantly more cost effective considering the size of the monitoring area.

There are limitations to consider when utilizing satellitebased InSAR [14]. It is essential to understand the expected velocity rate so image timing is appropriate. There is an upper limit on the amount of deformation that can be measured between two images, even with the unwrapping of multiple phase shifts. Five fringes are the normal upper limit that can be expected with some level of confidence, although higher numbers of fringes have been observed. For a satellite that uses a $5.66 \mathrm{~cm}$ wavelength radar signal, this restriction means the maximum limit on measurable deformation between two images is $(5.66 \mathrm{~cm} \times 5) / 2=14$ $\mathrm{cm}$.

If the expected deformation in the chosen period is over $14 \mathrm{~cm}$, the deformation will not be measurable and will appear as noise. To overcome this limitation, the imaging frequency must be the same as measurement frequency. The measurement frequency is limited by the repeat time of the satellite orbit. In the case of TerraSAR-X, the maximum rate is four days between images. This frequency requires the sensor to be adjusted to the opposite side looking position. If the same side is maintained, the rate is 11 days [15].

Height error must also be considered when using InSAR. Organizations that operate the radar attempt to replicate the orbit paths exactly, but they can deviate from image to image. The distance between two imaging positions can vary from several meters to several hundred meters. Larger distances between imaging positions cause more significant height errors in the data. This happens because when the same spot is imaged from different locations, the small change in perspective results in a phase shift correlated with the distance between imaging positions. The phase change due to height error cannot be distinguished from the phase shift due to deformation without additional information. The height error can be corrected by using a known, accurate Digital Elevation Model(DEM) of the imaging area. The phase shift due to height error can be simulated for the known imaging positions. The affected height error phase difference can be removed from the original interferogram which leaves deformation as the primary source of the phase difference. Here, the DEM itself must be accurate, or else the correction itself will be a source of error.

The radar look geometry must be established before starting an InSAR imaging project. There are two specific issues with geometry that must be addressed: shadows and signal angles. Once the target monitoring area is identified, the potential look geometries can be analyzed to look for shadows. These are areas where steep terrain blocks the view of the radar signal. Another issue to address is the angle of the radar signal to the topography being monitored. The SAR signal positioning is based on ranging principles.
The signal must be directed at the topography at an oblique angle so the return signal of the topography closest to the radar returns sooner than the return signal reflected from the topography furthest from the radar. This allows the return signals to be sorted into range bins as they arrive at the radar. If the signal from the radararrives at the topography at a perpendicular angle, the reflected signals return to the radar at similar times. The signals cannot be distinguished. The correction for both of these issues is to change the direction of the radar look geometry.

Finally, InSAR measurements can be affected by losing coherence between two images. Coherence is the degree to which the surface characteristics are similar between two images. The position of the ground can change slightly, but if the shape of the ground changes the return signals will be different. This difference causes a loss of coherence. Any significant change in the character of the reflective surface will cause coherence loss. Densely vegetated areas are subject to coherence loss. Also, areas where the ground has been worked, such as mining or construction sites, can lose coherence. Areas, where the ground has displaced more than the amount that can be measured,lose coherence.

\section{ANALYSIS}

With active mining, the necessity to predict landslides and rock slope failures is a great concern. The aim of all geotechnical groups is to monitor structures to determine their stability but the question of when a geomechanical failure will occur is critical [16]. The prediction of the time of slope failure is a major goal, particularly at an active mine site, as a reasonably accurate prediction of the time of slope failure will avoid human loss, reduce damages to property, and provide time to designadequate countermeasures [17]. When trying to assess rock failure mechanism, it is important to understand the structure geology, groundwater, climate, rock mass strength, in situ stress conditions, and seismicity [18].

Despite all the systems available to help monitor slope stability such as global positioning systems (GPS), slope stability radars (SSR), extensometers, prisms and many more, there is always the question of when an unstable area might collapse and result in a failure. Monitoring is used in mines to anticipate possible acceleration in mine slopes or possible failure of a moving slope mass [18]. The consequence of slope failure can be managed with the availability and capacity of the modern slope radar monitoring equipment to scan the slope face within a few minutes and detect sub-millimeter displacement [19]. A method that can predict the failure time of the mine slope based on the rate of movement is required toachieve manageable slopes.

It is important to understand the different possible movements before a slope failure in order to make a safe failure time prediction. Before a slope collapses, many signs indicate a slope approaching its failure stage. However, not all kinds of displacement will be an indicator of slope failure. Most severe slope instabilities are predominantly 
accompanied by developing tension cracks behind the slope surface and a measurable displacement [5]. The opening of a tension crack that is visible to the naked eye is usually the first sign that a slope is approaching an unstable condition [17]. An increase in displacement typically can be recorded by monitoring systems until the slope collapses or until the movement of the slope is too fast for the radar to capture. As the slope progresses to a failure, progressive, steady or regressive movements become evident. Zavodni and Broadbent [20] identified progressive and regressive stages of a failure based on empirical data from several open pit mines. The terms progressive and regressive might cause confusion so they can also be termed as unstable and stable movements respectively. When a slope displacement continues to accelerate to the point of collapse, it is known as a progressive displacement curve or unstable movement (Fig-2). If the slope is decelerating or stabilizing, this movement is called the regressive displacement curve or stable movement (Fig-3). It has been identified that if a regressive movement causes a failure, it is usually a response to some mining activity near the affected area [21]. When there is some displacement in the slope, but no acceleration or deceleration is noticeable, it is known as a steady displacement curve (Fig-4).

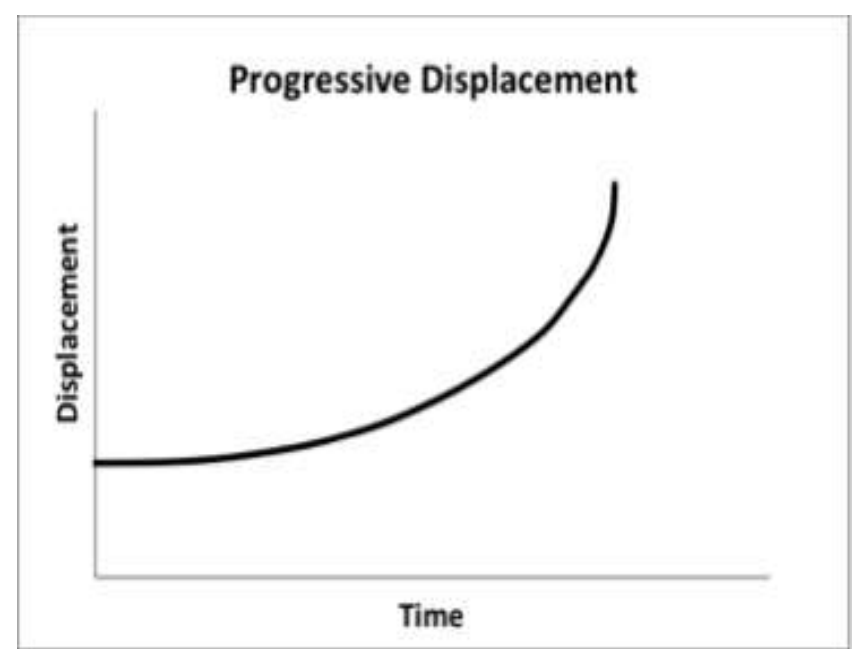

Fig-2: Progressive Displacement

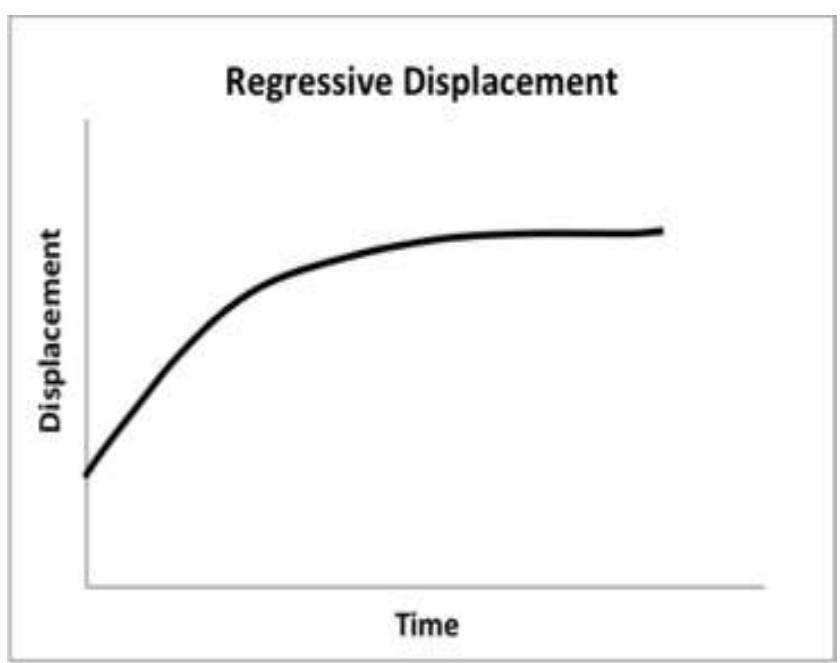

Fig-3: Regressive Displacement
Creep and displacement curves go hand-in-hand. The simplest definition of creep is "time-dependent deformation of solids under stress," this is crucial in slope stability studies, given that before visible displacement significant creep deformations develop in all slopes [22]. Much of the materials susceptible to creep display very similar behavior of time-strain. Creepcan be described in three simple stages: primary creep with a decreasing strain rate; secondary creep during which the strain rate is constant;tertiary or accelerated creep that displays rapid increasing strain rate leading to a failure [17].Primary creep relates to regressive displacement; secondary is the same as steady movement, and tertiary creep is similar to progressive displacement.

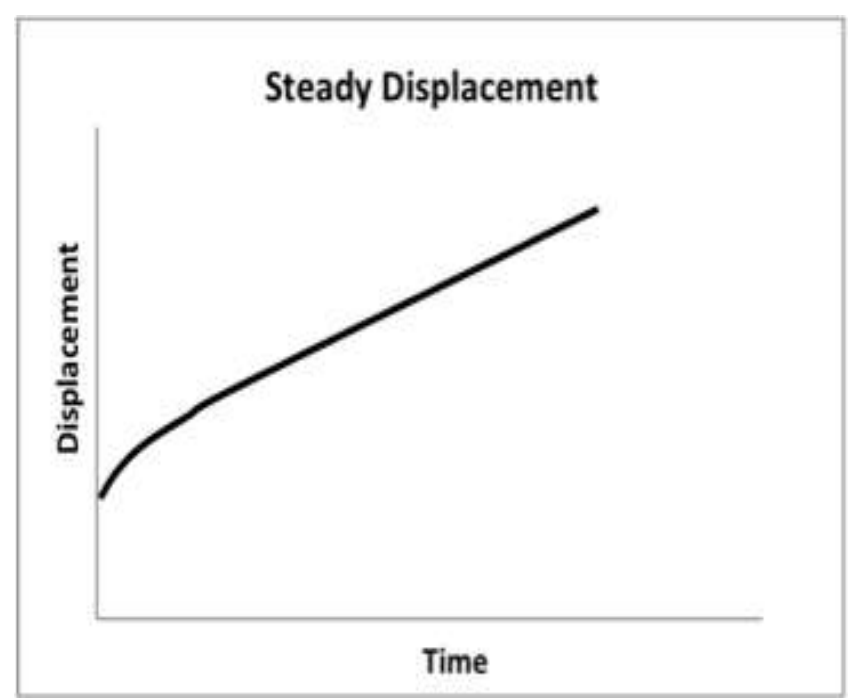

Fig-4: Steady Displacement

As different displacements indicate a slope might be actively moving it is important to predict possible time of failure. One of the most important reasons to predict slope failure is to keep employees safe and give people working in the hazardous area time to evacuate. To allow ample time for evacuation, prediction must occur before the failure takes place. An annotated diagram of a safe and unsafe prediction is displayed in Fig-5. In the diagram, red line $A B$ represents the actual life expectancy of the slope. At point B we see $\mathrm{Tf}$, representing the real time of failure. If the prediction of the slope failure is madein the time below the line $A B$ it could be a safe prediction; this allows for evacuation or emergency preparedness before any failure occurs [16]. If the prediction is made in time above the line $\mathrm{AB}$ it will be an unsafe prediction; this physically means that the failure will occur before the predicted time of failure, giving anyone working in the area insufficient time to evacuate [16].

Predicting the time of slope failure is of high priority for all active mining sites. Some methods used in the past and continue to be used today have been described. Along with predicting the time of slope failure, it is useful to know the potential of slope failure. Many studies of these methods utilize accelerating creep theory or progressive movement of the slope to make the slope failure predictions tuned to sitespecific conditions. It is crucial to understand that, in reality, all slopes cannot depend on the creep theory and can be 
largely dominated by processes or mechanics not affected by creep [16]. Some processes that can be unrelated to creep include structural instabilities, weather effects, the strength of rock, etc.

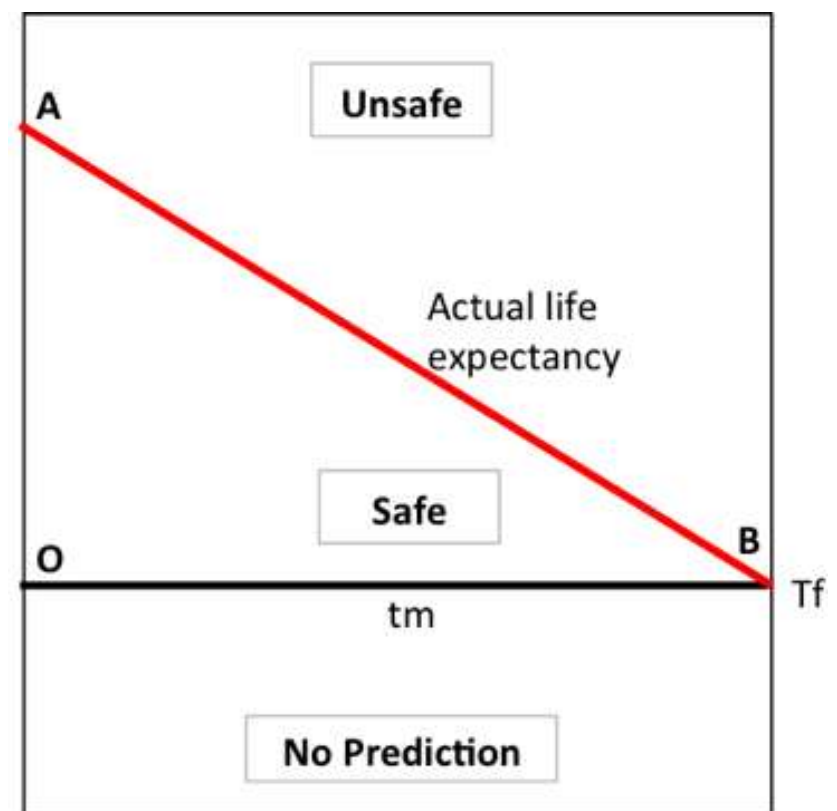

Fig-5: Distinction between a safe and unsafe prediction, line $\mathrm{AB}$ represents actual time of failure

\subsection{Inverse Velocity}

Based on previous Japanese work, Fukuzono [23] developed the concept of inverse-velocity for predicting time of slope failure using large-scale well-instrumented laboratory tests simulating rain-induced landslides in soil. Time of slope failure is predicted by projecting a trend line through a graph of inverse velocities versus time. The point at which the projected line intersects the time axis is the failure prediction time. Fukuzono [23] fitted three plots to the laboratory data, i.e., concave, convex and linear plots defined by the equation below:

$$
V^{-1}=[A(\propto-1)]^{1 / \alpha-1}\left(t_{f}-t\right)^{1 / \alpha-1}
$$

In the equation $t$ is time, $\mathrm{A}$ and $\propto$ are constants and $t_{f}$ is the time of failure. Based on laboratory tests Fukuzono [23] concluded that a linear fit usually gives a close estimate of the failure prediction time, shortly before the failure.

The inverse velocity method can be performed in a few simple steps. The first step is to obtain the inverse rate of displacement. When the monitoring data set reaches a progressive displacement stage, the displacement versus time data can be extracted and the time interval between each scan is measured. For the measured scan time interval, the displacement rate can be calculated. After the displacement rate has been obtained it is converted to inverse velocity for further calculations. Slope failure predictions cannot be made if the displacement trend is unclear or lasts for a short period [19]. The majority of the monitoring systems used today already have this information calculated in the analysis section itself, allowing direct extraction of the inverse velocity. Once inverse velocity data are obtained, the second step is to do a simple linear regression of the inverse rate of displacement. The inverse rate of displacement method is based on the linear relationship between two variables, inverse rate of displacement and time [19]. The equation $y=m x+b$ is used for a best-fit line of linearity trend. The third step is to fit a regression line through the data on a graph of inverse velocity versus time. The last step is to extend the linear regression line to intersect the time axis, the point of intersection will be the failure time prediction. Note with passing time the rate of progressive displacement of the slope might change and this will modify the inverse velocity. To avoid errors, keep making these predictions to get a close estimate of the actual time of failure. As the real time of failure approaches the time prediction becomes ambiguous, the inverse velocity will never approach zero since the velocity will never approach infinity.

\subsection{Evaluation of Slope Failure Potential using}

\section{Fuzzy Neural Network}

Slope stability is a critical subject for geomechanical engineers. The slope stability depends highly on the geology and surrounding environmental conditions. Naturally occurring characteristics like geology and environmental conditions usually cannot be assigned a numerical value to solve resulting slope stability problems; this uncertainty keeps slope stability fascinating and research-worthy. An approach capable of dealing with the uncertainty of these stability aspects is essential. For the past few decades, the fuzzy set theory has been gaining interest especially in civil engineering research and is slowly being adopted in studies of slope failure. Many people have tried to use fuzzy sets and the fuzzy neural network approach to analyze potential slope failure. This method will not help in predicting the time of failure but will assist in preparedness for a potential slope failure.

The fuzzy set was introduced by Zadeh [24] as a class of objectives with a continuum of grades of membership; a set is characterized by a membership function which will assign each object in the set a grade ranging between zero and one. In a conventional engineering system, the fuzzy set concept is the model adopted for analysis that can be deterministic or probabilistic [25]. Studies have used the neural network approach to evaluate the stability of a slope whereby fuzzy sets represent the parameters of the neural network [26]. In machine learning, the neural network is a system inspired by the biological neural network and is used to estimate functions depending on a large number of unknown inputs. Although the artificial neural networks are a simplified version of the biological neural network, they retain enough of a structure to provide information of how biological neural networks might operate [27]. The neural network can learn to accumulate knowledge and experience from the unknown inputs received. Because of this ability, artificial neural networks can be used to evaluate the failure potential of a slope [26]. 
Neural networks are machines designed to model the way brains perform a particular task of interest. These networks are constructed from neurons, artificial parallel operating systems, connected to a circuit-like system. A neuron is a unit with the capability to perform a trivial function that will produce an output $\mathrm{Y}$ based on input $\mathrm{X}$ based on the relationship defined below: [26].

$$
\begin{aligned}
Y_{i}=f\left(\text { net }_{i}\right) & \\
\text { net }_{i} & =\sum_{j}\left(W_{j i} X_{j}-\theta_{i}\right)
\end{aligned}
$$

where: net $_{i}=$ weighted input from all $i$ th neurons

$Y_{i}=$ output value of $i$ th neuron

$W_{j i}=$ Weight of input data $\left(X_{j}\right)$ from the $j$ th neuron

$X_{j}=$ input value of the $j$ th neuron

$\theta_{i}=$ weighted biases of the $i$ th neuron

$f=$ transfer or activation function

The most common and straightforward neural network is comprised of three layers: the input layer, the hidden layer, and the output layer. Neural networks can be categorized as supervised or unsupervised; a supervised neural network is trainedto produce the desired output in response to a set of inputs, whereas an unsupervised neural network is formed by letting the network continually adjusting to new inputs [27].

A good example of the neural network in slope stability is the work of Juang [25]. Juang considers four categories of factors that can affect slope stability: geology, topography, meteorology and environmental. He subdivides each of these into 2 to 5 elements each resulting in 13 factors as his inputs. Theinputsaretreated as linguistic variables. Five linguistic grades, each represented by a fuzzy number, are selected to characterize the effect of each factor on the failure potential. The five fuzzy numbers are: very high, high, moderate, low and very low. Many trial-and-error attempts were made with these parameters before the network topology of this study was established.

After the initial study of the use of neural networks for the prediction of slope stability, many successful studies have been performed. Using real-world data sets, Sakellarios and Ferentinou [27] applied the neural network theory to investigate the accuracy and flexibility of the method, for circular, plane and wedge failure mechanisms. Wang, W. $\mathrm{Xu}$, and $\mathrm{R} \mathrm{Xu} \mathrm{[28]} \mathrm{used} \mathrm{aback} \mathrm{propagation} \mathrm{neural} \mathrm{network}$ to evaluate the slope stability of the Yudonghe landslide. In this study, they used a four-layer back propagation neural network model with five input nodes, two hidden layers, and two output nodes. In a study conducted by Hwang, Guevarra and $\mathrm{Yu}$ [29], general slope factors were analyzed and classified using a decision tree algorithm to evaluate the validity of a Korean slope database comprised of 6,828 slope observations. In another study, Lin, Chang, Wu and Juang [30] created an empirical model to estimate failure potential of highway slopes using failure attributes specific to highway slopes in the Alishan, Taiwan area before and after the 1999 Chi-Chi, Taiwan earthquake. Beyond those listed, there are many more studies that have used neural networks to assess slope instability.

\section{DISCUSSION}

The ultimate objective of a geotechnical mining engineer in an open pit mine is to successfully manage any slope stability risk posed to personnel, equipment, and continued production. Risk management is incorporated into pit slope designs either explicitly or implicitly. Despite precautions taken during the design phase of a mine, unforeseen slope instability issues have occuredin the past and continue to be a problem today [31]. Pit slopes are designed based on exploration data collected throughout the life of the mine. During exploration, major geological structures and rock types can be identified but smaller structures can remain unknown. Identified and unidentified geological structures are important factors in the stability of the slopes as these geological structures together form the rock mass. Discontinuities in the rock are what cause movement in pit slopes during and after mining, ranging from small micro cracks to plate boundaries of the earth [5]. When the rock type, discontinuities, and other factors of the rock mass are put together, the strength of the large-scale rock mass can be determined to predict if a slope failure will occur in any given area.

Sjoberg [5] identified primary factors that govern large-scale slope stability as:

1. The internal stress acting on the slopes of the pit including the stress and effects caused by groundwater

2. The presence of large geological structures

3. The geometry and the steepness of each sector of the pit

4. The overall rock mass strength

It is common practice to identify the steepest possible slope angles for the mine to reduce the stripping ratio, which directly affects the economy of any mining operation [5]. Final pit limits are identified not only by ore grade distribution but also rock strength and stability, is it important to closely monitor the slopes of all active and inactive parts of a mine. Real-time monitoring is required to identify slope movement and define adequate preventive measures for possible landslide emergencies [32].

Today it has become a standard practice to use slopemonitoring radars for active monitoring of pit walls. Spatial distribution of slope movements is easy to understand with efficient use ofradar units. Slope monitoring radars have emerged in the last ten years as a cuttingedge tool for safetycritical monitoring of pit wall movement. Radars are increasingly usedbecause of theirability to measure slope changes with a sub-millimetric accuracy over a wide area and in any weather conditions without needing to install additional instruments such asreflectors or prisms [34].Additionlly, the progressive movement alerts provided by radar units help provide a safe work environment for personnel and can result in increased mine productivity [33].

Monitoring radars have allowed for the effective use of slope data to keep pit walls safe. The deformation versus time data collected helps make predictions possible for slope failure time. However, all radar systems have one limitation. Monitoring systems use wavelengths to measure the 
displacement between each scan. Thus, the restriction on the radar is the amount of displacement that can be measured during each scan. If the displacement is greater than the value that can be measured, there is a possibility of missing significantmovement altogether. This problem can be avoided with the help of careful visual observation and appropriate analysis of the data available.

The overall numbers of fatalities in the mining industry have reduced in the past decade. The total number of surface mine fatalities in 2005 was 28 compared to 43 fatalities in 1998. Along with the reduced total fatalities, the number of fatalities associated with slope failure has also reduced. McHugh, Long and Sabine [1] stated that there was a total of 42 surface mine fatalities between 1995 and 2003.The average over that time period is approximately 4.7 fatalities per year. The average number of fatalities from 1995 to 2015 have reduced from approximately five per year to zero. The increased use of radar technology for risk management analysis in many open pit mines is easily justified by the reduced numbers of fatalities, demonstrated in Table-1. As new technologies emerge and are adopted in a timely manner the number of fatalities and accident will be reduced.

Table-1: Number of slope failure related fatalities in all the metal, non-metal surface mines in the United States [35-48].

\begin{tabular}{|c|c|c|c|}
\hline Year & $\begin{array}{c}\text { Total fatal } \\
\text { accidents }\end{array}$ & $\begin{array}{c}\text { Fatalities } \\
\text { from falling } \\
\text { highwall (\%) }\end{array}$ & $\begin{array}{c}\text { Total number } \\
\text { of slope related } \\
\text { fatalities }\end{array}$ \\
\hline 1998 & 43 & 2.3 & $\mathbf{1}$ \\
\hline 1999 & 43 & 4.6 & $\mathbf{2}$ \\
\hline 2000 & 40 & 5 & $\mathbf{2}$ \\
\hline 2001 & 22 & 0 & $\mathbf{0}$ \\
\hline 2002 & 37 & 2.7 & $\mathbf{1}$ \\
\hline 2003 & 24 & 0 & $\mathbf{0}$ \\
\hline 2004 & 24 & 4.1 & $\mathbf{1}$ \\
\hline 2005 & 28 & 0 & $\mathbf{0}$ \\
\hline 2006 & 25 & 8 & $\mathbf{2}$ \\
\hline 2007 & 26 & 0 & $\mathbf{0}$ \\
\hline 2008 & 15 & 0 & $\mathbf{0}$ \\
\hline 2009 & 15 & 0 & $\mathbf{0}$ \\
\hline 2010 & 17 & 0 & $\mathbf{0}$ \\
\hline 2011 & 11 & 0 & $\mathbf{1}$ \\
\hline 2012 & 12 & 8.3 & $\mathbf{0}$ \\
\hline 2013 & 17 & 5.8 & $\mathbf{0}$ \\
\hline 2014 & 23 & 0 & \\
\hline 2015 & 14 & 0 & \\
\hline
\end{tabular}

Radars are a leading technology in the mining industry today to help keep mine slopes safe but to successfully use them, it is vital to understand all the limitations of the technology. Theunpredictability of slope movements is an exciting field of study and to manage slope stability risks it is important to understand all aspects that can affect the movement of the slope. Monitoring equipment can be a great advantage if limitations of the technologyareaccounted for during its use. The technology itself is not the end-all tool to assess slope stability, analysis of monitoring data to make predictions is necessary.

\section{REFERENCES}

[1] McHugh, E.L., Long, D.G. and Sabine, C. 2004. Applications of Ground-Based Radar to Mine Slope Monitoring. ASPRS Annual Conference. Proceedings, Denver, Colorado

[2] Rai R. CHAPTER3: TYPES OF ROCK SLOPE FAILURE.[Online] Available at:http://www.iitbhu.ac.in/faculty/min/rajeshrai/NMEI CTSlope/Pdf/03\%20Type\%20of\%20slope\%20failure.p df. [Accessed 10 June 2016]

[3] Hoek, E., and Bray, J.W. 1981. Rock Slope Engineering. London: Institution of Mining and Metallurgy

[4] Hoek, E.1970. Estimating the stability of excavated slopes in opencast mines. Transactions of the Institution of Mining and Metallurgy 79, No. 767, A109-A132.

[5] Sjoberg, J. 1996. Large Scale Slope Stability in Open Pit Mining - A Review. Technical Report. Division of Rock Mechanics, Lulea University of Technology.

[6] Osasan, K.S., and Afeni, T.B. 2010. Review of Surface Mine Slope Monitoring Techniques. Journal of Mining Science, Vol. 46, No. 2.

[7] Girrard, J. M. 2001 Assessing and Monitoring Open Pit Mine Highwalls. Proceedings of the $32^{\text {nd }}$ Annual Institute of Mining Health, Safety, and Research, Salt Lake City, Utah.

[8] Kayesa, G. 2006. Prediction of slope failure at Letlhakane Mine with the Geomos Slope Monitoring System. Proceedings of the International Symposium on Stability of Rock Slopes in Open Pit Mining and Civil Engineering Situations, Series S44, South Africa (2006).

[9] Pieraccini, M. 2013. Real Beam vs. Synthetic Aperture Radar for Slope Monitoring. Progress in Electromagnetics Research Symposium Proceedings, Stockholm, Sweden.

[10] Afeni, T.B., and Cawood, F.T. 2013. Slope monitoring using Total Station: What are the Challenges and How Should These be Mitigated?South African Journal of Geomatics, Vol. 2, No. 1.

[11] Call, R.D. and Savely, J.P. 1990 Open Pit Rock Mechanics. Surface mining, $2^{\text {nd }}$ edition. Society of Mining, Metallurgy, and Exploration, Inc.

[12] Ding, X., Montgomery, S.B. and Tsakiri, M. 1998 Integrated Monitoring Systems for Open Pit Wall Deformation. Australian center of Geomechanics, MERIWA Project Report.

[13] Lu, Z., and Dzurisin, D. 2014. InSAR imaging of aleutian volcanoes: Monitoring a volcanic arc from space. New York; Heidelberg: Springer.

[14] Read, J., Stacey, P. 2009. Guidelines for open pit slope design. Collingwood, Vic; Leiden, Netherlands: CSIRO Pub.

[15] Kramer, H. 2015. Terra-SAR X mission. eoPortal. [Online] Available at: https://directory.eoportal.org/web/eoportal/satellitemissions/t/terrasar-x [Accessed 1 June 2016].

[16] Mufundirwa, A., Fujii, Y. and Kodama, J. 2010. A new practical method for prediction of geomechanical failure-time. International Journal of Rock Mechanics\& 
Mining Sciences 47: 1079 - 1090.

[17] Federico, A., Popescu, M., Eila, G., Fidelibus, C., Interno, G., and Murianni, A. 2012. Prediction of time to slope failure: a general framework. Environmental Earth Science 66: 245 - 256.

[18] Rose, N.D. and Hungr, O. 2007. Forecasting potential rock slope failure in open pit mines using the inversevelocity method. International Journal of Rock Mechanics \& Mining Sciences 44: 308 - 320.

[19] Osasan, K.S., and Stacey, T.R. 2014. Automatic prediction of time of failure of open pit mine slopes based on radar monitoring and inverse velocity method. International Journal of Mining Science and Technology 24: $275-280$.

[20] Zavodni, Z. M., and Broadbent, C. D. 1978. Slope Failure Kinematics. Preprint Proceedings $19^{\text {th }}$ US Symposium on Rock Mechanics, Vol 2, p. 86 - 94

[21] Call, R. D., Cicchini, P. F., Ryan, T. M., and Barkley, R. C. 2000. Managing and Analyzing Overall Pit Slopes. In Hustrulid, W. A., McCarter, M. K., and Van Zyl, D. J. A., Slope Stability in Surface Mining, p. $39-$ 46.

[22] Tavenas, F., and Leroueil, S. 1981. Creep and failure of slopes in clays. Canadian Geotechnical Journal 18(1): 106 - 120

[23] Fukuzono, T. 1985. A new method for predicting the failure time of a slope. In: Proceedings of the fourth international conference and field workshop on landslides. Tokyo: Japan Landslide Society; p. 140 150.

[24] Zadeh, L. A. 1965. Fuzzy sets. Information and control 8, p. $338-353$.

[25] Juang, C. H., Lee, D. H., and Sheu, C. 1992. Mapping slope failure potential using fuzzy sets. Journal of Geotechnical Engineering, ASCE, 118 (3) p. 475 494.

[26] Ni, S. H., Lu, P. C., and Juang, C. H. 1996. Fuzzy neural network approach to evaluation of slope failure potential. Microcomputers in Civil Engineering 11 p. $56-66$

[27] Sakellariou, M. G., and Frentinou, M. D. 2005. A study of slope stability prediction using neural networks. Geotechnical and Geological Engineering 23: 419 225.

[28] Wang, H. B., Xu, W. Y., and Xu, R. C. 2005. Slope stability evaluation using back propagation neural networks. Engineering Geology 80 p. 302 - 315.

[29] Hwang, S., Guevarra, I. F., and Yu, B. 2009. Slope failure prediction using a decision tree: A case of engineered slopes in South Korea. Engineering Geology 104 p. 126 - 134.

[30] Lin, H. M., Chang S. K., Wu, J. H., and Juang, C. H. 2009. Neural network-based model for assessing failure potential of highway slopes in the Alishan, Taiwan area: Pre- and post- earthquake investigation. Engineering Geology 104 p. 280 - 289.

[31] Harries, N. Noon, D. and Rowley, K. 2006. Case studies of slope stability radar used in open cut mines. Proceedings of Stability of Rock Slopes in Open Pit Mining and Civil Engineering Situations, Cape Torn, South Africa, p. 335 - 342.
[32] Casagli, N., Catani, F., Del Bantisette, C., and Luzi, G. 2010. Monitoring, prediction, and early warning using ground-based radar interferometry. Landslides 7: p. $291-301$

[33] Farina, P., Coli, N., Yon, R., Eken, G., and Ketizmen, H. 2013. Efficient real time stability monitoring of mine walls: The Collolar mine case study. $23^{\text {rd }}$ International Mining Congress and Exibition of Turkey, p. 111 117.

[34] Farina, P., Coli, N., Coppi, F., Babboni, F., Leoni, L., Marques, T., and Costa, F. 2014. Recent advances in slope monitoring radar for open-pit mines. Proceeding of Mine Closure Solutions. Ouro Preto, Minas Gerais, Brazil.

[35] Anon., 1999. The Metal-Nonmetal Monitor, 1998 Fatal Accidents.[Online] Available at:http://arlweb.msha.gov/fatals/monitor/MONIT98.PD F[Accessed 20 November 2016].

[36] Anon., 2000. The Metal-Nonmetal Monitor, 1999 Fatal Accidents.[Online] Available at: http://arlweb.msha.gov/fatals/monitor/MONIT99.PDF [Accessed 20 November 2016].

[37] Anon., 2001. The Metal-Nonmetal Monitor, 2000 Fatal Accidents.[Online] Available at: http://arlweb.msha.gov/fatals/monitor/MONITOR2000. PDF [Accessed 20 November 2016].

[38] Anon., 2001. The Metal-Nonmetal Monitor, 2001 Fatal Accidents. [Online] Available at: http://arlweb.msha.gov/fatals/monitor/MONITOR2001. PDF [Accessed 20 November 2016].

[39] Anon., 2004. The Metal-Nonmetal Monitor, 2002 Fatal Accidents. [Online] Available at: http://arlweb.msha.gov/fatals/monitor/monitor2002.pdf [Accessed 20 November 2016].

[40] Anon., 2004. The Metal-Nonmetal Monitor, 2003 Fatal Accidents. [Online] Available at: http://arlweb.msha.gov/fatals/monitor/monitor2003.pdf [Accessed 20 November 2016].

[41] Anon., 2005. The Metal-Nonmetal Monitor, 2004 Fatal Accidents.[Online]Available at: http://arlweb.msha.gov/fatals/monitor/monitor2004.pdf [Accessed 20 November 2016].

[42] Anon., 2005. The Metal-Nonmetal Monitor, 2005 Fatal Accidents. [Online] Available at: http://arlweb.msha.gov/fatals/monitor/monitor2005.pdf [Accessed 20 November 2016].

[43] Anon., 2007. The Metal-Nonmetal Monitor, 2006 Fatal Accidents. [Online]Available at: http://arlweb.msha.gov/fatals/monitor/monitor2006.pdf [Accessed 20 November 2016].

[44] Anon., 2007. The Metal-Nonmetal Monitor, 2007 Fatal Accidents. [Online] Available at: http://arlweb.msha.gov/fatals/monitor/monitor2007.pdf [Accessed 20 November 2016].

[45] Anon., 2009. The Metal-Nonmetal Monitor, 2008 Fatal Accidents. [Online] Available at: http://arlweb.msha.gov/fatals/monitor/monitor2008.pdf [Accessed 20 November 2016].

[46] Anon., 2010. The Metal-Nonmetal Monitor, 2009 Fatal Accidents. [Online] Available at: http://arlweb.msha.gov/fatals/monitor/monitor2009.pdf 
[Accessed 20 November 2016].

[47] Anon., 2010. The Metal-Nonmetal Monitor, 2010 Fatal Accidents. [Online] Available at: http://arlweb.msha.gov/fatals/monitor/monitor2010.pdf [Accessed 20 November 2016].

[48] Anon., 2015. METAL/NONMETAL FATALITY END OF THE YEAR REPORT - December 31, 2015. [Online] Available at: http://arlweb.msha.gov/stats/charts/mnm-eoy2015.asp[Accessed 20 November 2016].

\section{BIOGRAPHIES}

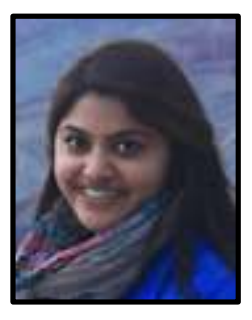

Upasna Chandarana earned a Bachelor's and Master's degree in Biosystems Engineering and is currently working on her Ph.D. in Mining Engineering at The University of Arizona. Her research topic is "Optimizing Geomechanical Risk Management Analysis"

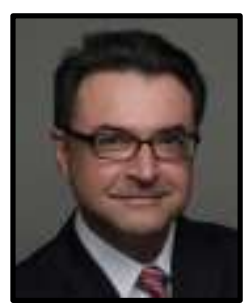

Moe Momayez is an Associate Professor of Mining \& Geological Engineering, and Geosensing and Energy Team Leader at the Lowell Institute for Mineral Resources, University of Arizona. His expertise is in rock physics, geomechanics, instrumentation, mine ventilation and renewable energy.

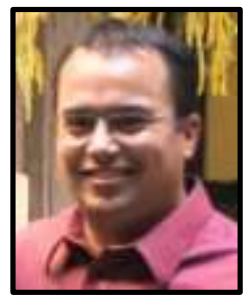

Keith Taylor has worked in rock mechanics and open pit slope stability since 2006. He has managed open pit slope stability programs at mine sites in Arizona and New Mexico. In his current role, Keith works with slope stability teams on projects at all of Freeport's mining operations. 